\title{
Aspectos do Projeto Político Pedagógico do Movimento Escoteiro no Brasil e reflexos na Educação Ambiental
}

\author{
Camila Moreno de Lima Silva \\ Programa de Pós-graduação em Ensino e História \\ das Ciências da Terra - IGe - Unicamp \\ Rosely Aparecida Liguori Imbernon \\ Professor Associado da Escola de Artes, Ciências e \\ Humanidades - EACH - Universidade de São Paulo \\ - USP / Programa de Pós-graduação em Ensino e \\ História das Ciências da Terra - IGe - Unicamp
}

\begin{abstract}
Aspects of the Political-Pedagogical Project of the Scout Movement in BRaZil and IMPLICATIONS FOR ENVIROMENTAL EDUCATION. - The objective of this paper is to show the Boy Scout Movement as a possibility to include Geoscience Education for Environmental Education activities to children and youth. This model of teaching within a extraescolar movement may produce some reflections on school education. The Boy Scout Movement was established by Robert Stephenson Smyth Baden-Powell (B-P) in 1907 and worldwide is an educational movement, without lucrative purposes. It aims the development of the young, by means of a system of values that prioritizes honor. The system relies on the Promise and Boy Scout Law; the work in team and the life in outdoors help promoting activities of interpretation of the environment, and about the Earth dynamics. During the development of this work, the authors have collected data from the Brazil Boy Scout (UEB) as well as they have done interviews with participants of all the ages and professions. The objective is to evaluate if such a non-formal movement of education presents any effect on school education, and what aspects of the activities can be reproduced in Environmental Education for children and youth. Citation: Silva C.M.L., Imbernon R.A.L. 2014. Aspectos do Projeto Político Pedagógico do Movimento Escoteiro no Brasil e reflexos na Educação Ambiental Terræ Didatica, 10(3):425-435. http://www.ige.unicamp.br/terraedidatica/.
\end{abstract}

KEYWORDS: Environmental education, Boy Scout movement.

RESUMO O Movimento Escoteiro foi fundado por Robert Stephenson Smyth Baden-Powell (B-P) em 1907 eé um Movimento educacional mundial, voluntariado, apartidário e sem fins lucrativos. A proposta visa o desenvolvimento do jovem, por meio de um sistema de valores que prioriza a honra. Esse sistema se baseia na Promessa e Lei Escoteiras, $e$ o trabalho em equipe e a vida ao ar livre promove atividades com foco principal nas Ciências Naturais, de interpretação do meio ambiente, e de respeito às dinâmicas terrestres. Para o desenvolvimento deste trabalho, foi realizado um levantamento de dados junto aos Escoteiros do Brasil (UEB) e entrevistas com Escoteiros de todas as idades e profissões. O objetivo foi demonstrar como um movimento de ensino extraescolar apresenta reflexos na educação escolar, e aspectos da Educação Ambiental presentes nas atividades realizadas pelas crianças e jovens.

PALAVRAS-CHAVE: Educação Ambiental, Movimento Escoteiro. 


\section{Introdução}

O Movimento Escoteiro (ME) foi fundado por Robert Stephenson Smyth Baden-Powell (B-P) em 1907 que inspirado pela força de vontade e amor à Pátria demonstrado pelos adolescentes durante a Guerra do Transvaal, na Inglaterra, Baden-Powell criou um programa de desenvolvimento para treinamento de soldados que foi divulgado como o livro "Aids to Scouting", traduzido como "Auxílio para o Escotismo". Baden-Powell notou diversos grupos de rapazes que utilizavam seu livro para guiar as brincadeiras; tal situação o estimulou a reescrever o livro, adaptando as imagens e linguagens para a idade e mentalidade dos rapazes.

Em Julho de 1907 organizou na Ilha de Brownsea um acampamento com 20 jovens convidados, e em cada dia do acampamento realizou atividades variadas e atraentes com os principais temas de seu livro: técnicas de acampamento, observação, artes mateiras, cavalheirismo, salvamento de vidas, patriotismo etc. O sucesso do acampamento foi tão grande que em 1908, Baden-Powell publicou seu livro "Escotismo para Rapazes", que foi vendido em fascículos em adas as-lojas e bancas de jornal. Como resultado de sua publicação o movimento se espalhou por várias regiões ultrapassando os limites da Inglaterra, chegando a outros países.

Ao notar a necessidade de dedicar mais tempo aos jovens através do Escotismo, Baden-Powell afastou-se do exército e passou a organizar o Movimento Escoteiro. Em 1920 foi realizado o primeiro grande acampamento mundial, chamado de Jamboree Mundial, no qual se reuniram Escoteiros de várias nacionalidades e Baden-Powell foi nomeado Chefe Escoteiro Mundial. A partir de então, nem mesmo as duas grandes guerras mundiais enfraqueceram o Movimento Escoteiro, que se espalhou rapidamente pelo mundo (Tab. 1).

No mesmo período em que Baden-Powell realizava o acampamento na Ilha de Brownsea, em 1907, oficiais e praças da Armada Brasileira estavam na Inglaterra e ficaram impressionados

Tabela 1. Distribuição de Escoteiros pelo mundo (fonte: xww.escoteiros.org.br)

\begin{tabular}{c|l}
\hline Região Ásia - Pacífico & 23 países e 23 associações \\
\hline Região África & 40 países e 45 associações \\
\hline Região Inter-Americana & 31 países e 31 associações \\
\hline Região Árabe & 13 países e 13 associações \\
\hline Região Europa & 40 países e 68 associações \\
\hline Região Eurásia & 04 países e 05 associações \\
\hline
\end{tabular}

com o método de educação complementar que Baden-Powell idealizava. Os marinheiros trouxeram para o Brasil os ideais de B-P e o modelo dos uniformes escoteiros para introduzir o movimento no país. Em 14 de junho de 1910 foi fundado, no Rio de Janeiro, o Centro de Boys Scouts do Brasil. A partir de 1914 surgiram outros núcleos Escoteiros por todo o país, e o principal deles foi a Associação Brasileira de Escoteiros (ABE) em São Paulo, que espalhou o Movimento Escoteiro por todo o Brasil.

O Escotismo ganhou verdadeira amplitude nacional em 1924, com a fundação da União dos Escoteiros do Brasil (UEB) no Rio de Janeiro, como unificadora dos grupos e núcleos Escoteiros espalhados pelo Brasil. Com o Decreto-Lei ${ }^{\circ}$ 8.828, de 24 de Janeiro de 1946, o Escotismo foi reconhecido no país como uma instituição extra-escolar, que pela sua natureza, enquadra-se entre as instituições escolares que visavam complementar a educação formal nas unidades de ensino o que se configurava como um procedimento comum no Brasil da redemocratização de 1946, após o Estado Novo de 1937 (Thomé 2006).

Ao refazermos o papel do Movimento Escoteiro na história da educação escolar na região de Santa Catarina, por exemplo, identificamos os problemas enfrentados no Brasil pelas similaridades com a organização clandestina da Juventude Hitlerista no Brasil, em face das características da educação no Brasil àquela época (Thomé 2006).

Paolillo e Imbernon (2009) destacam que o Escotismo, por envolver os princípios da cidadania, a formação do cidadão, a ética, e a vida em observação e respeito à natureza, apresenta componentes muito próximos àqueles propostos pela Educação Ambiental. Hintz e Thomson (2012) mostraram que o Movimento Escoteiro nos Estados Unidos da América é um dos maiores espaços de educação científica informal e educação em Geociências.

Estima-se que cerca de 450 milhões de jovens já passaram pelas fileiras do Escotismo nos últimos 100 anos, e atualmente esse movimento conta com um total de 28 milhões de filiados (UEB 2011). No Brasil, cerca de 70 mil brasileiros são Escoteiros; no estado de São Paulo, cerca de 20 mil famílias participam do Escotismo, e na cidade de São Paulo, mais de 17 mil adultos trabalham voluntariamente como educadores, gestores de unidades locais 
Tabela 2. Ramos do Movimento Escoteiro (fonte: www.escoteiros.org.br)

\begin{tabular}{|c|c|c|}
\hline RAMO & GRUPO & FAIXA ETÁRIA / ATIVIDADES \\
\hline Ramo Lobo & Alcatéia & $\begin{array}{l}\text { Para meninos e meninas entre } 7 \text { a } 10 \text { anos, chamados de Lobinhos e Lobinhas. Usa } \\
\text { como marco simbólico o livro da Jângal, de Rudyard Kipling. As atividades incentivam a } \\
\text { socialização pela diversão e execução de tarefas em equipes. }\end{array}$ \\
\hline Ramo Escoteiro & Tropa Escoteira & $\begin{array}{l}\text { Para meninos e meninas entre } 11 \text { a } 14 \text { anos, chamados de Escoteiros e Escoteiras. É } \\
\text { baseado no estudo da natureza, vida mateira, exploração, campismo, navegação e conquista } \\
\text { do ar, fundamentado na vida em equipe e participação comunitária. }\end{array}$ \\
\hline Ramo Sênior & Tropa Sênior & $\begin{array}{l}\text { Para meninos e meninas entre } 15 \text { a } 17 \text { anos, chamados de Seniores e Guias. Tem suas } \\
\text { atividades em torno dos quatro desafios: físico, mental, espiritual e social, atendendo às } \\
\text { características da idade de auto-afirmação, intenso desenvolvimento físico e intelectual. }\end{array}$ \\
\hline Ramo Pioneiro & Clã Pioneiro & $\begin{array}{l}\text { Para meninos e meninas de } 18 \text { a } 21 \text { anos, chamados de Pioneiros e Pioneiras. É uma } \\
\text { fraternidade de ar livre e serviço ao próximo, funcionando como um centro de interesses, } \\
\text { de realização, de mútua ajuda e de serviço comunitário, promovendo atividades de } \\
\text { campismo, excursionismo e ecológicas, culturais e sociais, estimulando o jovem a evoluir } \\
\text { em espiritualidade e perfeição humana e atingir a maturidade como cidadão feliz e } \\
\text { eficiente. }\end{array}$ \\
\hline
\end{tabular}

de Escotismo e em sua estrutura organizacional, bem como na capacitação de outros adultos voluntários (UEB 2012). Embora com pequenas alterações, o Movimento Escoteiro segue os mesmos princípios e métodos propostos por B-P em todas as regiões do planeta, no qual os jovens são separados em grupos (Alcatéia, Tropa Escoteira, Tropa Sênior ou Clã Pioneiro) e ramos (Lobo, Escoteiro, Sênior ou Pioneiro) para participarem de atividades adaptadas a cada faixa etária (Tab. 2).

Independentemente do Ramo a que pertencem, os jovens participam de atividades programadas pelos adultos integrantes do Movimento Escoteiro, chamados de Escotistas. Todas as atividades programadas prezam os princípios e métodos do Movimento Escoteiro, elaborados a partir do Projeto Político Pedagógico que envolve conteúdo das Ciências Naturais, tem abordagens da Educação Ambiental inseridas nas atividades com as crianças e jovens (Paolillo e Imbernon 2009). B-P associava o estudo da natureza- ao utilizar elementos dos meios biótico e abiótico, e conteúdo da Biologia, no estudo de plantas e animais, e das Geociências, sempre associados à busca da felicidade (Hintz e Thomson 2012).

O Método Escoteiro estabelece um sistema de progressão com a intenção de estimular que os jovens desenvolvam suas capacidades e seus interesses, incentivando a superação de desafios, a exploração, o desejo por aventura, a descoberta, a iniciativa, a invenção, a criação, etc. Para atingir tais metas, baseia-se na aceitação da "lei e promessa escoteiras; aprender fazendo; vida em equipe; atividades progressivas, atraentes e variadas; e desenvolvimento pessoal com orientação individual”.

Os elementos básicos a partir dos quais o Escotismo se fundamenta, por um lado, envolvem sua própria definição, e por outro, seus propósitos, princípios e métodos, que em conjunto são denominados de fundamentos (Vallory 2013).

Em 1977, durante a Conferência Mundial Escoteira, a Constituição da World Organization of the Scout Movement (WOSM) foi modificada, incorporando de forma mais clara os propósitos, princípios e método a partir de uma visão mais moderna dos fundamentos (WOSM 1977). Os três elementos que compões os fundamentos no Escotismo, envolvem o porquê ele existe (propósito); que regras éticas que governam sua existência (princípios); e como ele vai atingir o seu objetivo (método educacional) (WOSM 1977).

Assim, enquanto os fundamentos (propósitos, princípios e método) envolvem elementos ideológicos do escotismo, a definição foca as características desse tipo de organização. Os elementos da definição são tão importantes quanto os fundamentos, e determinam o que o escotismo é, e o que não é (Vallory 2013). Desta forma, as razões pelas quais o escotismo, como organização mundial, pode suspender o reconhecimento de uma associação escoteira são: controle governamental, falta de independência, partidarismo, obrigação e discriminação.

Cabe ressaltar que o movimento escoteiro assume muitas formas, ao se adaptar ao contexto social de cada país, independentemente do contexto político, social ou religioso; dessa forma, a característica essencial é a denominação comum, a ser adotada por toda e qualquer organização membro. Essa característica permite a discussão de um único assunto em nível global (Vallory 2013).

De acordo com Henri Joubrel, autor do livro O Escotismo na Educação e Reeducação dos Jovens (Jou- 
brel 1969), a importância atual do Escotismo e a influência que exerceu desde sua criação são fatos incontestáveis. De forma que Schmidt, em seu livro Educar pela Recreação (Schmidt 1964) afirma que

“... o Escotismo foi, sem dúvida, uma das invenções mais geniais que têm surgido no campo pedagógico. Quando os sociólogos de amanhã estudarem a história da juventude, verão ainda melhor do que nós a que ponto as 'simples sugestões' lançadas em 1908, por Baden-Powell, contribuíram para a evolução das ideias sobre educação e como formaram um determinado tipo de indivíduo".

De fato, para Joubrel (1969), alguns componentes psicossociais podem ser associados com elementos do Movimento Escoteiro; Paollilo e Imbernon (2009) identificaram tais elementos ao desenvolver atividade de educação ambiental com crianças do ME, identificando um conhecimento do meio físico e do meio ambiente melhor elaborado, daquele que geralmente observamos em grupos de crianças não escoteiros.

Esse aspecto é inerente ao Movimento Escoteiro, que busca estimular nos jovens o respeito e o compromisso com a natureza, com os indivíduos e consigo próprio. E, pela aplicação e prática do Projeto Educativo do Movimento Escoteiro, é possível que sejam formados cidadãos saudáveis, justos e úteis para a sociedade, como sempre desejou Baden-Powell.

Desta forma, os objetivos deste trabalho focaram-se em realizar um levantamento de dados, por meio de entrevistas, junto ao Escritório Nacional dos Escoteiros do Brasil (UEB) sobre as orientações pedagógicas que delinearam as ações junto aos Grupos Escoteiros no Brasil; realizar entrevistas com Escotistas de todas as idades durante eventos escotistas regional e internacional; identificar reflexos na formação para a cidadania e avaliar os tipos de atividades aplicadas com foco em conteúdo de Geociências e Educação Ambiental.

\section{Delineamento da pesquisa}

Adotamos os referenciais da pesquisa qualitativa a partir das definições de Bogdan e Biklen (1982), que abordam aspectos considerados essenciais em estudos que se utilizam de tal metodologia, cujas caraterísticas básicas envolvem elementos que estão associados aos cenários/atores que protagonizaram esse estudo:

- a pesquisa qualitativa utiliza-se do ambiente natural como fonte direta de coleta de dados e tem o pesquisador como instrumento fundamental para esta coleta: as coletas de dados com os membros do movimento escoteiro foram realizadas em eventos Escotistas, ambiente natural de encontro e desenvolvimento das atividades escoteiras; os pesquisadores são membros de grupo escoteiro e já participaram de eventos semeslhantes;

- éuma pesquisa descritiva; o investigador preocupa-se, essencialmente, com o significado que as pessoas dão as coisas e a sua vida: o instrumento de pesquisa, na forma de questionário, direcionou dois tipos de indagações, um conjunto de caracterização individual dos respondentes (origem, idade, tempo no movimento, escolaridade) de cunho mais quantitativo, e outro que envolveu uma reflexão do respondente sobre o papel do movimento em sua vida profissional, em sua formação de cidadão, etc. Tal abordagem seguiu modelo anteriormente aplicado por Silva (2012), de forma a compor um perfil dos respondentes, e para que os Escotistas dessem depoimentos sobre sua ótica (de membro do movimento), sem interferência do pesquisador.

Nesta mesma perspectiva, também foram realizadas entrevistas não estruturadas com os dirigentes do movimento, em Curitiba.

- uso do enfoque indutivo na análise dos dados: realização de generalizações de observações limitadas e específicas pelo pesquisador/Escotista. De fato, muitas das respostas requereram conhecimento da estrutura e metodologias que envolvem o movimento Escotista, pertinente somente a quem participa como membro escoteiro.

Os levantamentos realizados junto à população escoteira por meio dos questionários com jovens e Escotistas membros do Movimento Escoteiro (ME) durante a realização do Acampamento Regional de Patrulhas, ARP 2011, na cidade de Paulínia, em São Paulo $(n=44)$. Identificamos Escotistas de 10 diferentes cidades do estado de São Paulo, e dos estados do Paraná, Rio Grande do Norte e Santa Catarina. Todos os participantes e respondentes autorizaram a entrevista e respostas aos questionários.

Os resultados dos questionários foram transcritos e constituíram um conjunto de dados que foram quantitativamente analisados. Cabe ressaltar que as categorias para compor as tabelas emergiram do diálogo entre os dados obtidos e as referências teóricas, construindo assim o material de análise.

Todos os participantes e respondentes autorizaram a entrevista e respostas aos questionários.

A observação de atividades escoteiras aconteceu durante o acampamento VJamboree Nacional Esco- 
teiro, realizado no Rio de Janeiro em Julho de 2012, e analisadas as diferentes formas como os Escotistas abordam os conteúdos do currículo escolar em suas atividades, principalmente com foco em Geociências, e transversalmente questões sobre meio ambiente. $\mathrm{O}$ evento reuniu membros do Movimento Escoteiro da Bahia, Ceará, Distrito Federal, Espírito Santo, Goiás, Maranhão, Mato Grosso, Mato Grosso do Sul, Minas Gerais, Paraná, Rio de Janeiro, Rio Grande do Sul, Santa Catarina, São Paulo, e representantes da França, México e Paraguai.

Foram registradas observações de nove atividades Escoteiras, dentre as 12 realizadas durante o evento. As atividades registradas foram: qualidade da água; teatro ecológico; fogão solar de espelhos; dinâmica das ilhas; planejamento urbanístico de uma cidade sustentável; história de um desastre natural; preparação para um desastre; elaboração de projetos; e inclusão social.

Algumas características que são identificadas em pesquisas qualitativas, tais como a visão do ambiente natural como fonte direta de dados, o caráter descritivo, o enfoque indutivo e, principalmente, o significado que as pessoas dão às coisas e à sua vida, foram elementos importantes para a pesquisa.

Dessa forma, a pesquisa qualitativa, como abordagem metodológica neste trabalho, teve o objetivo de traduzir e expressar o sentido dos fenômenos do mundo social, especificamente no âmbito do Movimento Escoteiro, tratando de reduzir a distância entre a teoria e os dados.

Consideramos que há uma relação dinâmica entre a aprendizagem espontânea promovida pelas atividades nos grupos escoteiros e o conhecimento geocientífico, que deveria compor os conteúdos do ensino formal. As entrevistas e questionários propostos aos respondentes foram uma das etapas de levantamentos, depois completadas e comparadas à pesquisa documental e bibliográfica realizadas na UEB. Assim, buscamos entender fenômenos segundo a perspectiva dos participantes da situação estudada (atuação no Movimento Escoteiro) e, com base nos levantamentos, situamos nossas interpretações.

\section{Resultados}

\section{Respostas aos questionários: perfil dos respondentes e análise das respostas}

A caracterização dos respondentes pelo nome, idade, profissão, região e numeral do Grupo Escoteiro foi formalizada durante as entrevistas, somente para orientarmos um tratamento quantitativo dos respondentes e compor um perfil do grupo; e as questões objetivas se focaram, fundamentalmente, a como o Movimento Escoteiro esteve (ou está) envolvido no desenvolvimento da cidadania, seja em sua vida acadêmica, profissional e/ou pessoal; que elementos da vida Escoteira promoveram o conhecimento científico e, de que forma a percepção do meio ambiente foi (ou é) afetada pela participação no movimento.

Assim, dentre os respondentes, o membro do ME mais jovem tem 17 anos, e o mais velho 65 anos de idade. No quesito "tempo em que são Escoteiros", o membro que participa há menos tempo é Escoteiro há 6 meses, e o que participa há mais tempo é Escoteiro há 57 anos.

Ao propormos questionamento que aborda o tipo de escola em que o entrevistado estudou (ou estuda), 25 membros estudaram (ou estudam) apenas em escola pública, 11 membros estudaram (ou estudam) apenas em escola particular e 8 membros estudaram (ou estudam) em ambos os tipos de escola (pública e particular).

Ao contrário do que incialmente pressupúnhamos, o Movimento Escoteiro tem uma forte abrangência na escola pública, dado confirmado quando entrevistamos o diretor da regional do Paraná, em Curitiba, descaracterizando a premissa inicial de que o movimento apresentasse caráter elitista.

Quando questionados sobre "como chegou até o Movimento Escoteiro", os resultados obtidos foram classificados em seis categorias (Fig. 3): divulgação na escola em que estudava (ou estuda) $(4,54 \%)$; por indicação de familiares que participaram (ou participam) do Movimento Escoteiro $(47,73 \%)$; ouviu falar $(2,27 \%)$; por indicação de amigos que participaram (ou participam) do Movimento Escoteiro (29,55\%); foram convidados para auxiliar na fundação de um Grupo Escoteiro

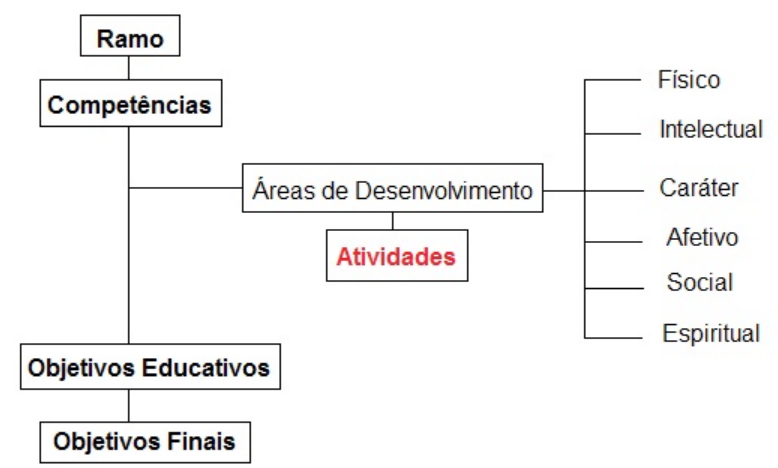

Figura 1. Método escoteiro para o desenvolvimento de competências por ramo escoteiro (fonte: elaborada por Camila M. L. Silva) 
(9,09\%); e viram os Escoteiros realizarem atividades em parques e demonstraram interesse (6,82\%).

Alguns dos principais objetivos buscados pelo Movimento Escoteiro são que o jovem aprenda a ter liderança, saiba trabalhar em equipe, tenha respeito ao próximo e seja capaz de enfrentar desafios. Tais objetivos foram verificados pelas respostas obtidas com as entrevistas realizadas nos levantamentos realizados durante ARP 2011, em Paulínia.

\section{Observação das atividades escoteiras em evento internacional}

Em continuidade aos levantamentos realizados em reuniões e eventos escotistas, durante o acampamento V Jamboree Nacional Escoteiro, realizado no Rio de Janeiro em julho de 2012, foram feitos levantamentos das diferentes formas como os Escotistas abordam os conteúdos do currículo escolar em suas atividades (especialidades para obtenção de distintivos de méritos), principalmente com foco em Geociências, e transversalmente questões sobre meio ambiente.

O responsável pelo método educativo na UEB em Curitiba (PR) relatou durante o período desta etapa da pesquisa de campo realizada no Jamboree, que "o sucesso na aplicação do Método Escoteiro é auxiliado pela capacidade que as pessoas têm de mudar sua conduta, seja por sugestão, por permitir que seja contagiado ou por desejo". O Escotista definiu que a sugestão ocorre quando alguém em quem o jovem confia mostra as vantagens e desvantagens de assumir uma "boa conduta" e a sugere ao jovem que, por confiar nele, assume esta posição, o jovem realmente gosta e se identifica com aquilo que the foi ensinado e então muda sua conduta, sem precisar de influência externa e sim apenas por desejo de que assim se realize.

Durante o evento, foram registradas observações de 9 atividades Escoteiras, dentre as 12 realizadas durantes o evento. Avaliaram-se as formas como foram abordados conteúdo do currículo escolar, relacionados ao meio ambiente. As atividades registradas foram: qualidade da água; teatro ecológico; fogão solar de espelhos; dinâmica das ilhas; planejamento urbanístico de uma cidade sustentável; história de um desastre natural; preparação para um desastre; elaboração de projetos; e inclusão social.

Para melhor analisar as principais características de cada atividade, caracterizamos todas as atividades pelo título, objetivo e procedimento, salientando que no procedimento indicamos as reflexões sugeridas durante a atividade:

Atividade 1: Qualidade da Água - objetivo adquirir a noção da diferença entre uma amostra de água suja e outra limpa. Após uma breve explicação sobre a utilização dos kits de análise de água, cada equipe teve 30 minutos para coletar e analisar duas amostras de água: uma no curso d'água adjacente à área de acampamento e outra do ponto de onde saem os esgotos (água dos chuveiros) do Parque de Tiro, onde foi realizado o evento. Após a análise, os dados foram comparados e os jovens discutiram as diferenças entre as amostras.

Reflexões: Quais foram as observações feitas pelos Escoteiros? Como a água que eles analisaram se encaixa no ciclo da água? Para onde vai a água depois de sair de nossas casas e o que acontece com ela?

Atividade 2: Teatro Ecológico - objetivo desenvolver a criatividade na criação de uma pequena peça de teatro cujo tema é biodiversidade.

Cada equipe teve 30 minutos para preparar uma breve peça de teatro que tivesse um enfoque ecológico e um propósito educativo sobre o tema biodiversidade. Foram preparadas pequenas estórias fornecidas para as encenações, caso as Patrulhas tivessem dificuldade no delineamento da peça de teatro.

Reflexões: Qual é a moral da estória? As Patrulhas compreenderam o que significam "ecossistemas" e "biodiversidade"? Qual é a importância de se preservar o habitat das espécies? Que atitudes adotamos no dia-a-dia que podem afetar a existência de tais habitat?

Atividade 3: Fogão Solar de Espelhos - objetivo reconhecer diferentes formas de energia que podemos utilizar para diminuir o impacto ao meio ambiente.

Usando a argila, as Patrulhas alinharam os pedaços de espelho sobre a placa de Eucatex olhando através do suporte de metal. A folha numerada deve estar no teto de um quiosque para que os jovens não olhem para o sol durante a montagem do fogão.

Reflexões: Que outras formas de energia podemos utilizar para diminuir o impacto ao meio ambiente? Como nossas escolhas afetam o gasto de energia da sociedade? Como diminuir o gasto de GLP ao cozinhar?

Atividade: Dinâmica das Ilhas - objetivos adquirir a noção da importância do diálogo entre as Nações para resolver os graves problemas ambien- 
tais, principalmente o de aquecimento global.

Foram distribuídos pedaços de papelões em número igual ao de jovens participantes, que serão as ilhas, dispostos em círculo. Cada jovem representou um país. Alguns papelões foram colocados mais longe dos demais. O Chefe então informa que todos deverão se mover sobre os papelões de forma a formar uma fila que vai do mais jovem ao mais velho, ou seja, por ordem de data de nascimento. Ninguém pode pôr os pés no chão. Vai levar um tempo para que os jovens se organizem.

Reflexões: Quando terminarem, o Chefe dará a interpretação: "se vocês, que são jovens, conseguiram cumprir essa tarefa, por que os países não podem se organizar e diminuir a emissão de carbono para a atmosfera? Todos os jovens contribuíram para a solução do problema porque se uniram em torno de um objetivo. Porque nós não podemos nos unir em torno do objetivo de sermos sustentáveis?". Questões: O que foi mais difícil na dinâmica? Como incentivar o diálogo entre as Nações? Como nossas decisões no dia-a-dia influem na emissão de carbono e no aquecimento global?

Atividade 4: Planejamento Urbanístico de uma Cidade Sustentável - objetivos reconhecer a função e importância de um planejamento urbanístico.

As Patrulhas montaram uma pequena cidade sustentável com módulos fornecidos pelos Chefes das Patrulhas. O objetivo era localizar serviços que temos nos centros urbanos na melhor posição possível: a estação de tratamento de água próxima ao curso d'água e numa posição elevada em relação à cidade; o depósito de lixo deve estar a favor do vento (sota-vento), etc. Após as discussões entre os jovens, a Patrulha chama o Chefe para mostrar sua solução para o problema, defendendo sua proposta. O objetivo não é forçar uma escolha de Parque em detrimento de Shopping, por exemplo, mas levar a Patrulha a questionar as vantagens e desvantagens de cada um e qual o mais adequado à cidade em questão.

Reflexões: Quais foram os itens mais difíceis de alocar na cidade e por quê? Vocês escolheram o cemitério ou o crematório, parque ou shopping, aterro sanitário ou estação de reciclagem, e por quê? Que conselhos vocês dariam aos planejadores urbanísticos?

Atividades5 e 6: História de um Desastre Natural - objetivo reforçar a importância da preparação e da tomada de decisões em uma situação de desastre natural.

Cada Patrulha recebeu um cartão com um cenário de desastre natural e terá 30 minutos para preparar uma pequena peça de teatro que represente a estória descrita no cartão.

Preparação para um Desastre - objetivo reforçar a importância da preparação para um desastre natural.

O chefe da base fará uma breve instrução sobre desastres naturais como deslizamentos de terra, enchentes, períodos de seca intensa, etc. e como nos preparar para esses eventos. Em seguida foi realizada uma atividade lúdica (jogo) em que os objetos eram sugeridos (água, alimentos, celular, telefones de emergência, lanterna com pilhas, etc.) e os jovens deveriam escolher quais objetos levariam com a Patrulha para lugares onde há risco eminente de desastres naturais.

Reflexões: De que desastres os jovens já tinham ouvido falar? Alguém já passou por uma experiência assim?

Atividades 7 e 8: Elaboração de Projetos - objetivos adquirir noções básicas para a elaboração de um projeto.

O chefe da base fará uma breve introdução sobre como fazer um bom projeto, enfatizando a sua viabilidade e exequibilidade. Cada Patrulha elaborou um pequeno projeto fictício para atuar na sua comunidade: projeto de recolhimento e reciclagem de óleo; projeto de recolhimento e destinação adequada de pilhas e baterias; projeto de recolhimento e reciclagem de papel; plantio de mudas; recuperação de uma pequena praça próxima ao Grupo Escoteiro; projeto de divulgação da importância do combate à dengue; projeto de núcleo de ajuda à Defesa Civil em caso de catástrofes; projeto de pesquisa de áreas de risco para ajuda à Defesa Civil na prevenção de catástrofes, entre outros.

Inclusão Social - objetivo vivenciar a dificuldade que pessoas com deficiências enfrentam no dia-a-dia e reconhecer a importância que temos ao incluí-las na sociedade.

Cada Patrulha deve vendar os olhos de um membro (representará uma pessoa cega), prender um dos braços de outro membro (representará uma pessoa com deficiência em um dos braços) e sentar um dos membros na cadeira de rodas (representará uma pessoa cadeirante). A atividade consiste em 3 partes: decifrar o código Morse, laçar o bambolê com o sisal utilizando nós Escoteiros e, por fim, montar e desmontar a barraca. Os três membros deficientes devem participar ativamente, com auxílio dos demais integrantes da Patrulha.

Entrevistas na UEB-Curitiba: A produção de 
material de orientação pedagógica para o Brasil

A análise dos manuais e projetos políticos pedagógicos do ME e as três entrevistas com dirigente Escoteiros do Brasil - UEB, em Curitiba, nos permitiu estabelecer como se dá o direcionamento das ações desde a World Organization of the Scout Movement (WOSM) até os grupos escoteiros em cada cidade do Brasil. Verificamos que embora as diretrizes estejam centradas na WOSM, na condição de uma definição e fundamentos, há uma adequação em diferentes níveis, continental, nacional, regional etc., até a adequação ao grupo escoteiro.

Os tipos de atividades propostas e a inserção de conteúdos de Geociências e Educação Ambiental dependem dos chefes e assistentes de tropa escoteira. De fato, as atividades dependem de formação previa dos monitores e do interesse do jovem nos temas, pois serão eles que decidirão o que querem aprender.

Para a América Latina, a Região Interamericana, que se localiza na "Cidade do Saber", na cidade do Panamá, define e envia as orientações, sugerindo temas. Os materiais, em sua maioria, são oriundos da Organização Interamericana; no Brasil, uma equipe de voluntários mesclada com uma equipe de profissionais na UEB trabalha nos materiais, adaptando-os para as realidades locais. Do ponto de vista organizacional, a figura de um Gerente Sênior de Métodos Educativos coordena o trabalho, que, posteriormente, um Gerente de Adultos delineará questões relacionadas ao treinamento. A produção de material, encargo da Gerencia de Programas, coordena um trabalho construído coletivamente, entre profissionais e voluntários. Não necessariamente o material é adotado de forma "idêntica" ao da região Interamericana, pois são guardadas as questões de adaptação local, nomenclatura etc.

Assim, as Organizações têm autonomia para constituir seu programa dentro do Método Escoteiro e adaptá-las às realidades nacionais, tendo como orientações o programa proposto pela região Interamericana.

Segundo a UEB houve uma grande mudança ao final da década de 80 com relação ao programa e a aplicação do Método Escoteiro. Os objetivos foram aproximar a prática pedagógica da realidade dos jovens, e uma mudança de "roupagem", metodologia, envolveu uma proposta de trabalho com competências e objetivos educativos muito mais forte do que se realizava anteriormente. Até a década de 80 valorizava-se a prática Escoteira,
(...) então se media a técnica, se o menino sabia ou não fazer um nó, se ele sabia montar uma barraca e tudo mais, atualmente, a gente dá muito mais valor pelo que tem por trás disso do que pela prática em si, segundo o coordenador entrevistado. Então, quero dizer, não importa muito se o menino sabe ou não fazer um nó, mas importa mais a competência que ele adquire usando o nó como ferramenta.

No livro Manual do Escotista Ramo Sênior: um método de educação não-formal para jovens de 15 a 17 anos (UEB 2011) define-se por competência a união do conhecimento, habilidade e atitude em relação a algum tema específico. Assim, propõe-se que o Escotista deva "saber algo" (conhecimento), mas, também, deva "saber fazer" (habilidade) para a aplicação do conhecimento e, ainda, "saber ser" (atitude) em relação ao que sabe e faz, uma conduta que revela a incorporação de valores (Fig. 1).

Para atingir esse objetivo, cada jovem deve cumprir uma série de competências divididas em atividades que buscam fazer com que ele (jovem) desenvolva habilidades, atitudes e conhecimento sobre técnicas, atividades e condutas, que estão divididas em seis áreas de desenvolvimento: físico, intelectual, caráter, afetivo, social e espiritual, efetivando, assim, o Método Escoteiro atual (Fig. 1).

Cabe ressaltar que em um dos referenciais didáticos, o livro Programa de Jovens: Objetivos finais e intermediários (UEB 2010), a proposta de objetivos educativos e finais:

“...contemplam tipos diferentes de conduta. Alguns entre eles propõem a aprendizagem de um determinado conteúdo (saber algo), enquanto outros se orientam para a incorporação de alguma atitude (saber ser) e/ou motivam uma ação específica (saber fazer)"

Desta forma, a partir de um Sistema de Distintivos, o jovem receberá distintivos de especialidades quando demonstrar saber aplicar as técnicas (montar barraca, construir fogões, etc.) e distintivos especiais de progressão por seu desenvolvimento pessoal.

A educação em Geociências, neste contexto, pode ser o foco, como demonstrado por Hintz e Thomson (2012). Os autores ao estudarem o movimento escoteiro no EUA identificaram distintivos de mérito em Geologia, em Conservação, e em Astronomia, que proporcionam aos jovens experiências que envolvem Ciências da Terra e do Universo, criando, desta forma, aprendizagem 
em Geociências. O estudo partiu da hipótese que jovens Escotistas que participaram de especialidades para obtenção de distintivo de mérito em Geologia, apresentariam um conhecimento mais especializado em geociências em relação a jovens Escotistas que não haviam participado.

Assim, jovens Escotistas que participaram do programa de distintivos de mérito (especialidades) em Geociências apresentaram maior conhecimento em geociências, quando comparados os resultados de atividades a jovens Escotistas que tiveram os mesmos conteúdos somente em aulas de geociências na escola (Hintz e Thomson 2012).

Esse melhor desempenho, segundo os autores, é justificado, pois o primeiro grupo construiu o conhecimento geológico a partir de experiências, memórias, e conhecimento adquirido a partir das atividades que participaram.

\section{Discussão}

As entrevistas realizadas com membros Escotistas de diferentes regiões, diferentes faixas etárias e tempo no movimento, e com dirigentes regionais e nacionais do movimento, indicaram que, independentemente do contexto social ao qual o jovem pertença, os fundamentos (propósitos, princípios e método) são os mesmos, que por definição caracteriza o Movimento como uma organização.

O método educacional Escoteiro é definido como um sistema de autoeducação progressivo, cuja estrutura pouco foi alterado, e basicamente envolve: (i) a promessa e a lei escoteira; aprender fazendo; (ii) associação de pequenos grupos, envolvendo adulto em orientação, e a descoberta progressiva e aceitação da responsabilidade e formação para o auto orientação dirigida para o desenvolvimento do caráter, e aquisição de competências, autossuficiência, confiança e capacidades, tanto para cooperar quanto liderar, e adesão à promessa e lei; (iii) programas progressivos e atividades variadas que estimulem os interesses dos participantes, incluindo jogos, habilidades e serviços à comunidade, organizados em grande parte, em um ambiente ao ar livre e em contato com a natureza.

Assim, identificamos no Movimento Escoteiro um ambiente educacional estruturado, ao considerarmos que uma das concepções espontâneas da sociedade é a de que educar é tarefa da escola. A isso se soma a complexidade do processo de ensino aprendizagem, pois se desenvolve em diversos ambientes: na escola, na família, na experiência do dia-a-dia etc. O método ME tem sido aplicado há mais de um século em ambiente de ensino não-formal. Tal observação é ressaltada nas entrevistas com Escotistas de diferentes idades, nível socioeconômico e grau de escolaridade, para os quais os fundamentos do escotismo são os mesmos, e baseiam-se, fundamentalmente, na Promessa e Lei Escoteira.

O Movimento Escoteiro, como forma de educação não formal, complementa a educação formal na medida em que auxilia a formação de cidadãos conscientes por meio de suas práticas, elementos destacados por Hintz e Thomson (2012) para jovens Escotistas nos EUA.

A definição de educação não-formal adotada para o Movimento Escoteiro é aquela definida pela Organização das Nações Unidas para a Educação, a Ciência e a Cultura (UNESCO), para a qual, educação formal é hierarquicamente estruturada, cronologicamente graduada, apresenta sistema educacional funcionando desde o primário até a instituições de ensino superior; a educação informal é o processo pelo qual cada indivíduo adquire atitudes, valores, habilidades e conhecimentos a partir da experiência diária, como da família, amigos, colegas, grupos, os meios de comunicação e outras influências e fatores no ambiente da pessoa; a educação não formal é a organização de atividade educacional fora do sistema formal estabelecido, que se destina a aprendizagem identificável com objetivos.

Cada um desses três tipos de educação desempenha um papel específico, que complementa os demais, e todos são necessários para formação e cidadania global. Em termos gerais: conhecimento e habilidades de trabalho são, geralmente, adquiridas pela educação formal; uma série de habilidades, tanto pessoais e sociais, são desenvolvidas pela educação informal; e a aquisição de competências para a vida e para o desenvolvimento de atitudes com base em um sistema integrado de valores é possível por meio da educação não formal.

A avaliação das atividades escoteiras nesta pesquisa durante os eventos Escotistas identificou temas bastante atuais, com foco na dinâmica terrestre, nos impactos gerados pelo meio antrópico sobre o sistema Terra, na reflexão geopolítica de uso e ocupação dos territórios, no papel que cada um deve assumir na sociedade, enquanto cidadão global. Os procedimentos, que partem de situações concretas, conduzem os jovens à abstração, por meio de questões, e à reflexão sobre os pro- 
blemas apresentados e das soluções propostas e/ ou alcançadas.

Tal procedimento tem como objetivo desenvolver habilidades e competências tanto no sentido da apreensão do conhecimento científico para sua plena realização, quanto permitir uma reflexão do jovem sobre qual a necessidade desse conhecimento em seu cotidiano, sua vida enquanto cidadão.

Ao analisarmos as atividades escoteiras programadas, e que se inserem no programa educativo do Movimento Escoteiro, observamos uma ampla variedade de atividades, cada uma com características próprias, estabelecidas a partir das orientações nacionais em Padrões de atividades escoteiras: um Manual para Escotistas e Dirigentes (Horn 2013). Em termos de objetivos, as atividades típicas escoteiras contribuem, de forma geral, para desenvolvimento pessoal das crianças e jovens.

No entanto, os autores destas diretrizes relatam que para alcançar algum interesse particular do grupo, uma atividade deve ser adequadamente organizada, ou seja, deve ter muito claro qual o seu objetivo. Tal perspectiva ficou evidente tanto na proposição de atividades para o evento, quanto no encaminhamento dado pelos monitores de realizar questionamentos aos participantes após a conclusão da atividade, impondo a cada jovem a reflexão sobre a ação.

Ao estudarmos o Movimento Escoteiro, encontramos uma organização e estrutura, denominados de Método Escoteiro, que têm sido aplicados em diferentes sociedades, em diferentes países, há mais de um século. Temas transversais como a Educação Ambiental, no âmbito das atividades escoteiras, apresentam "um ambiente no qual ensino formal e não-formal encontram uma linguagem comum e reconhecem no conhecimento científico estratégias de desenvolvimento social e cidadania" (Paolillo e Imbernon 2009).

\section{Conclusões}

O Movimento Escoteiro no Brasil tem sido um ambiente de aprendizagem que atua em paralelo à escola na formação de crianças e jovens há décadas. Entretanto, não se identificam estudos sobre o papel desse ambiente de educação social, tampouco, sobre como o conteúdo de Geociências é introduzido nas atividades desenvolvidas pelos grupos escoteiros.

A abordagem dos componentes curriculares de Geociências e o conhecimento do meio ambiente em atividades realizadas nos encontros evidenciou um enfoque especial relacionado ao meio físico; tal peculiaridade tem pautado as atividades desde as primeiras inserções de Baden Powell, para quem o contato direto com o meio ambiente, em acampamentos, trilhas, jornadas, atividades externas em geral, sempre foi um forte componente do método educacional escoteiro.

\section{Agradecimentos:}

As autoras agradecem ao UEB - Escritório Nacional da União dos Escoteiros do Brasil e à FAPESP- Processo 2012/18152-9.

\section{Referências Bibliográficas}

Baden-Powell G., Lord. 1986. Lições da escola da vida. $1^{\text {a }}$ ed. Curitiba: Escritório Nacional UEB-União dos Escoteiros do Brasil.

Baden-Powell G., Lord. 2006. Escotismo para rapazes: um manual de instrução em boa cidadania por meio das artes mateiras - Edição da Fraternidade Mundial. Curitiba: Escritório Nacional UEB-União dos Escoteiros do Brasil.

Baden-Powell G., Lord. 2006. Guia do Chefe Escoteiro: teoria do adestramento Escoteiro - um subsídio para a tarefa dos Escotistas - $7^{\mathrm{a}}$ Edição. Curitiba: Reproset Ind. Gráfica. p. 11-12, 28-30 e 45-62.

Carvalho J.O., Carvalho L.R.S.O. 2006. A educação social no Brasil: contribuições para o debate. In: Congr. Intern. Pedag. Soc., 1, 2006 . Proceedings online... Fac. Educ., USP. URL: http://www.proceedings.scielo.br/scielo.php?script=sci_arttext\& pid = MSC0000000092006000100024\&lng =en\& $\mathrm{nrm}=\mathrm{abn}$. Acesso em 05 Nov. 2013.

Gadotti M. 2005. A questão da educação formal/não-formal. International des Droits de L'enfant (ide). Droit à l'éducation: solution à tous les problèmes ou problème sans solution? Sion (Suisse), 18-22 outubro, 2005.

Gaspar A. 1992. O ensino informal de Ciências: de sua viabilidade e interação com o ensino formal à concepção de um centro de Ciências. Cad. Cat. Ens. Fis. 9(2):157-163.

Gaspar A. 2002. A educação formal e a educação informal em Ciências. In: Massarani L., Moreira I.C., Brito F. orgs. 2002. Ciência e público: caminhos da divulgação científica no Brasil. Rio de Janeiro: Fórum Ciência e Cult. Casa da Ciência. C. Cult. Ciência e Tecnol. Univ. Fed. Rio de Janeiro. p.171-183.

Hintz R., Thomson B. 2012. Geoscience education in the Boy Scouts of America. J. Geosc. Educ., 60:159-167. 
Joubrel H. 1969. O Escotismo na educação e reeducação dos jovens. Trad. Maria José Austregésilo de Athayde. Rio de Janeiro: Ed. Livr. Agir. p. 11-14, 24-29 e 94-103.

Ministério da Educação. MEC. 2011. PCNs - Parâmetros Curriculares Nacionais. São Paulo, 1996. URL: www.portal.mec.gov.br/seb/arquivos/pdf/livro01. pdf. Acesso em: Julho de 2011.

Neves J.L. 1996. Pesquisa qualitativa. Características, usos e possibilidades. São Paulo: Fac. Educ., USP, Cad. Pesq. Admin., 1(3):1-5. (Dissert. Mestr. Pós-Grad. Admin. Empresas) -

Paolillo C., Imbernon R.A.L. 2009. Educação Ambiental e educação científica no contexto do Movimento Escoteiro (Environmental and scientific education in the context of Boy Scouts Movement). Rev. Experiências no Ens. Ciências. 4(2):93-105.

Schmidt M.J. 1964. Educar pela recreação. Para pais e educadores. 3 ed. Rio de Janeiro: Ed. Agir.

Silva C.M.L. A. 2012. Contribuição do Movimento Escoteiro na Educação do Brasil: Aspectos do Projeto Político Pedagógico do Movimento e reflexos na educação para a cidadania. São Paulo: Esc. Artes, Ciênc. e Humanidades, EACH, USP. (Rel. PIBIC).

Thomé N. 2006. Movimento Escoteiro: projeto educativo extra-escolar. Universidade do Contestado (UnC), Campus de Caçador (SC). Revista HISTEDBR On-line. No 23. ISSN: 1676-2587.
Campinas, Setembro de 2006. Páginas 171-194.

União dos Escoteiros do Brasil. UEB. Escrit. Nac. 2008. Guia de Especialidades e Insígnia Mundial do Conservacionismo. $10^{\mathrm{a}} \mathrm{ed}$. Curitiba.

União dos Escoteiros do Brasil. UEB. Escrit. Nac. 2010. Programa de jovens: objetivos finais e intermediários. Curitiba.

União dos Escoteiros do Brasil. UEB. Escrit. Nac. s.d. Manual do Escotista Ramo sênior: um método de educação não-formal para jovens de 15 a 17 anos. Curitiba: UEB.

União dos Escoteiros do Brasil. UEB. Escrit. Nac. 2011. Escoteiros de São Paulo: relatório social e ambiental - 100 anos de história e de preservação do meio ambiente. São Paulo, UEB. p. 6-13.

União dos Escoteiros do Brasil. UEB. Escrit. Nac. 2011. Projeto Educativo do Movimento Escoteiro. Curitiba. URL: www.Escoteiros.org.br/downloads/ documentos_oficiais.php. Acesso fevereiro 2011.

União dos Escoteiros do Brasil. UEB. Escrit. Nac. 2011. Relatório Anual de 2011. URL: www.escoteiros.org.br. Acesso abril 2012.

União dos Escoteiros do Brasil. UEB. URL: www.escoteiros.org.br. Acesso fevereiro 2011.

Vallory E. 2013. World Scouting. Education for Global Citizenship. 2013. 1 ed. NY, USA.

World Organization of the Scout Movement, WOSM. 2008. URL: www.scout.org. Acesso fevereiro 2011. 